\title{
Heritability estimates and correlations between subjectively assessed and objectively measured fleece traits in Merino sheep
}

\author{
P. Naidoo ${ }^{1,2}$, S.W.P. Cloete ${ }^{1 \#}$ and J.J. Olivier ${ }^{3}$ \\ ${ }^{1}$ Elsenburg Agricultural Development Centre, Private Bag X1, Elsenburg 7607, South Africa \\ ${ }^{2}$ University of KwaZulu-Natal, Private Bag X01, Scottsville 3202, South Africa \\ ${ }^{3}$ Irene Animal Improvement Institute, Private Bag X5013, Stellenbosch 7599, South Africa
}

\begin{abstract}
Data from 2801 individuals (born from 1996 to 2002) were used to obtain heritability $\left(\mathrm{h}^{2}\right)$ estimates for five objectively measured and six linearly assessed type fleece traits (scored on a 1-50 point scale) from the Tygerhoek Merino flock. Correlations of the objective traits with the subjective traits were also derived. Estimates of $\mathrm{h}^{2}$ for the subjective traits accorded with literature estimates, and exceeded 0.2 for wool quality (0.31), wool colour (0.38), yolk (0.25), as well as belly and points (0.25). Corresponding $h^{2}$ estimates amounted to 0.19 for regularity of crimp score and 0.13 for staple formation score. Genetic correlations of objective traits with subjective traits were either favourable or negligible in the majority of cases. The only exceptions were positive genetic correlations of fibre diameter (FD) and coefficient of variation of FD with staple formation score and belly and points score. Genetic progress in subjective traits thus appears possible, if desired in a selection strategy.
\end{abstract}

Keywords: Correlations, heritabilities, linearly assessed traits, subjective wool traits

\#Corresponding author. E-mail: schalkc@elsenburg.com

\section{Introduction}

Commercial Merino breeders frequently use subjectively assessed wool traits in selecting breeding sires and dams. Linear type scoring was developed as a potential indicator of phenotypic and genetic indicators of production (Olivier et al., 1987) and has been used to obtain data in order to determine phenotypic correlations between some subjectively assessed fleece traits and objective wool traits (Cloete $e t$ al., 1992). Apart from the work of Snyman \& Olivier (2002) on genetic correlations of subjectively assessed fleece and conformation traits with production and reproduction in Afrino sheep, there is little information about the heritability and genetic relationships of these subjectively assessed traits with wool traits of economic importance. The usage of subjective traits as breeding objectives without knowledge of their relationships with other economically important traits could be counterproductive if correlations prove to be antagonistic. At the least, selection based on subjective traits could be ineffectual if genetic correlations are favourable but low.

This paper presents heritability estimates as well as genetic, phenotypic and environmental correlations between five objectively measured and six subjectively assessed fleece traits.

\section{Material and Methods}

The experimental animals belonged to a Merino flock maintained on the Tygerhoek Experimental Farm. Information regarding the selection and management of the flock are detailed elsewhere (Heydenrych et al., 1984). During the experimental period, 4 lines were represented (Cloete et al., 2001), namely a line selected on clean fleece weight, a fine wool line, a line selected against reproductive failure and an unselected control line. Clean yield (CY), clean fleece weight (CFW), staple length (SL), fibre diameter (FD) and the coefficient of variation of fibre diameter (CV) were assessed on 2801 animals of the flock from 1996 to 2002. Linear type scoring (Olivier et al., 1987) was used to assess the following subjective traits: quality (QUAL), regularity of crimp (ROC), colour (COL), oil content (YOLK), staple formation (STAPL) and belly and points (BANDP). All these traits were scored on a 1-50 scale.

The ASREML programme was used for the analysis of the data (Gilmour et al., 1999). The best random effects models were determined using log-likelihood ratios derived from single trait analysis on all the traits. Variance components and heritability estimates were derived from these runs. Genetic, environmental and phenotypic correlations of objective traits with subjective traits were subsequently computed by fitting tri-variate and bi-variate animal models using ASREML. 
Peer-reviewed paper: Joint South African Society for Animal Science/Grassland Society of Southern Africa Congress

\section{Results and Discussion}

The unadjusted means and ranges, as well as the direct additive animal variance ratios $\left(\mathrm{h}^{2}\right)$ and maternal genetic variance ratios $\left(\mathrm{m}^{2}\right)$ for the respective traits are presented in Table 1 . The qualitative wool traits CY and FD showed less variation than quantitative traits CFW and SL. Estimates of $h^{2}$ for these traits accorded with those summarised from the literature by Cloete et al. (2002). Corresponding $\mathrm{h}^{2}$ estimates were high ( $>0.2)$ for the majority of subjective traits, barring regularity of crimp and staple formation. These $h^{2}$ estimates concur with those obtained by Groenewald et al. (1999), with the exception of wool colour, for which a significantly higher value was obtained, 0.38 compared to 0.17 . Snyman \& Olivier (2002) estimated $\mathrm{h}^{2}$ for evenness of crimp in Afrinos as 0.28, which is somewhat higher than that estimated for regularity of crimp for Merinos in the present study (0.19).

Table 1 Number of records, means ( \pm s.d.), coefficients of variation (CV), direct additive animal variance ratios $\left(\mathrm{h}^{2}\right)$ and maternal genetic variance ratios $\left(\mathrm{m}^{2}\right)$ for objectively measured and subjectively assessed fleece traits in the Tygerhoek Merino flock

\begin{tabular}{lccccc}
\hline Trait & $\mathrm{n}$ & Mean \pm s.d. & $\mathrm{CV}(\%)$ & $\mathrm{h}^{2} \pm$ s.e. & $\mathrm{m}^{2} \pm$ s.e. \\
\hline Objective traits & & & & & \\
Clean yield (\%) & 2799 & $72.7 \pm 4.2$ & 5.8 & $0.64 \pm 0.04$ & - \\
Clean fleece weight $(\mathrm{kg})$ & 2740 & $3.5 \pm 1.0$ & 28.6 & $0.29 \pm 0.04$ & $0.06 \pm 0.02$ \\
Staple length (mm) & 2796 & $83.2 \pm 14.5$ & 17.4 & $0.25 \pm 0.04$ & - \\
CV of fibre diameter & 2801 & $20.2 \pm 3.1$ & 15.3 & $0.50 \pm 0.04$ & - \\
Fibre diameter $(\mu \mathrm{m})$ & 2801 & $19.8 \pm 1.7$ & 8.6 & $0.61 \pm 0.04$ & - \\
Subjective traits & & & & & - \\
Quality & 2700 & $30.3 \pm 8.7$ & 28.7 & $0.31 \pm 0.04$ & - \\
Regularity of crimp & 2700 & $31.5 \pm 8.4$ & 26.7 & $0.19 \pm 0.03$ & - \\
Colour & 2700 & $31.4 \pm 7.9$ & 25.2 & $0.38 \pm 0.04$ & - \\
Yolk & 2700 & $27.2 \pm 4.5$ & 16.5 & $0.25 \pm 0.04$ & - \\
Staple formation & 2700 & $27.4 \pm 5.1$ & 18.6 & $0.13 \pm 0.03$ & - \\
Belly and points & 2698 & $29.5 \pm 6.7$ & 22.7 & $0.25 \pm 0.04$ & - \\
\hline
\end{tabular}

On a genetic level, CY was favourably related to QUAL, COL, STAPL and BANDP (see Table 2). The genetic correlation with YOLK was negative. Genetic correlations of CFW with STAPL and BANDP were high and positive. No significant ( $\geq 2 \mathrm{X}$ the corresponding s.e.) correlation was found for SL and the respective subjective traits. Genetic correlations of CV and FD with QUAL and ROC were favourable and moderate to high. Corresponding correlations with STAPL were unfavourable, as was the genetic correlation of FD with BANDP. Environmental and phenotypic correlations between objective and subjective traits were mostly comparable in direction, albeit smaller in magnitude. Genetic correlations of evenness of crimp with objectively measured traits computed by Snyman \& Olivier (2002) agree with correlations obtained, with one notable exception. While no significant correlation was found for SL and the respective subjective traits, Snyman \& Olivier (2002) estimated a negative correlation of $-0.19 \pm 0.10$ of SL with evenness of crimp.

\section{Conclusion}

The study found that subjective wool traits were heritable and should respond to genetic selection when pursued as a breeding goal, without adverse effects on economically important objective traits. Estimates of $h^{2}$ for qualitative wool traits were generally larger in magnitude, while genetic correlations with subjective traits were either favourable or negligible. The only exception in this regard was STAPL, where high breeding values seemed to be unlikely for individuals with favourable breeding values for FD and CV.

\section{Acknowledgement}

The SA Wool industry provided material support for the establishment of the fine wool line.

\section{References}

Cloete, S.W.P., Greeff, J.C. \& Lewer, R.P., 2002. Direct and maternal genetic (co)variances for hogget liveweight and fleece traits in Western Australian Merino sheep. Aust. J. Agric. Res. 53, 271-279. 
Cloete, S.W.P., Olivier, J.J. \& Du Toit, E., 1992. Linear type traits in a Merino flock subjected to selection for increased clean fleece mass and an unselected control flock. S. Afr. J. Anim. Sci. 22, 70-73.

Cloete, S.W.P., Olivier, J.J. \& Du Toit, E., 2001. Blowfly strike of Merino sheep in relation to selection strategy, as well as to objective and subjective wool traits. Proc. Flystrike and Lice IPM Control Strategy Conf., 22-25 June 2001, Launceston, Tasmania. pp. 395-401.

Gilmour, A.R., Cullis, B.R., Welham, S.J. \& Thompson, R., 1999. ASREML, Biometric Bulletin, 3, NSW Agriculture, Orange Agricultural Institute, Orange, NSW.

Groenewald, P.G.J., Olivier, J.J. \& Olivier, W.J., 1999. Heritability estimates for Merino sheep obtained from a national progeny test. S. Afr. J. Anim. Sci. 29, 174-178.

Heydenrych, H.J., du Plessis, J.J. \& Cloete, S.W.P., 1984. Increasing the wool production of Merino sheep in the South Western Districts of South Africa by direct and indirect selection. Proc. $2^{\text {nd }}$ World Congr. Sheep Beef Cattle Breed., 16-19 April 1984, Pretoria. Eds. Hofmeyr, J.H. \& Meyer, E.H.H. South African Stud Book and Livestock Improvement Association, Bloemfontein (1984), 399-412.

Olivier, J.J., Delport, G.J., Erasmus, G.J. \& Eksteen, T.J., 1987. Linear type scoring in Merino sheep. Karoo Agric. 3, 1-4.

Snyman, M.A. \& Olivier, W.J., 2002. Correlations of subjectively assessed fleece and conformation traits with production and reproduction in Afrino sheep. S. Afr. J. Anim. Sci. 32, 88-96.

Table 2 Genetic $\left(r_{g}\right)$, environmental $\left(r_{e}\right)$ and phenotypic $\left(r_{p}\right)$ correlations of objective traits with subjective fleece traits in the Tygerhoek Merino flock

\begin{tabular}{|c|c|c|c|}
\hline Trait & $r_{g} \pm$ s.e. & $r_{e} \pm$ s.e. & $r_{p} \pm$ s.e. \\
\hline \multicolumn{4}{|l|}{ CY X } \\
\hline QUAL & $0.30 \pm 0.07$ & $0.10 \pm 0.05$ & $0.18 \pm 0.02$ \\
\hline ROC & $0.13 \pm 0.09$ & $0.05 \pm 0.04$ & $0.07 \pm 0.02$ \\
\hline COL & $0.53 \pm 0.06$ & $0.14 \pm 0.04$ & $0.33 \pm 0.02$ \\
\hline YOLK & $-0.45 \pm 0.07$ & $-0.15 \pm 0.05$ & $-0.26 \pm 0.02$ \\
\hline STAPL & $0.32 \pm 0.11$ & $-0.01 \pm 0.04$ & $0.09 \pm 0.02$ \\
\hline BANDP & $0.24 \pm 0.08$ & $0.06 \pm 0.05$ & $0.12 \pm 0.02$ \\
\hline \multicolumn{4}{|l|}{ CFW X } \\
\hline QUAL & $0.13 \pm 0.09$ & $0.05 \pm 0.04$ & $0.08 \pm 0.02$ \\
\hline ROC & $-0.05 \pm 0.11$ & $-0.06 \pm 0.03$ & $-0.05 \pm 0.02$ \\
\hline COL & $-0.03 \pm 0.09$ & $-0.04 \pm 0.04$ & $-0.04 \pm 0.02$ \\
\hline YOLK & $0.21 \pm 0.10$ & $0.16 \pm 0.04$ & $0.17 \pm 0.02$ \\
\hline STAPL & $0.52 \pm 0.10$ & $0.21 \pm 0.03$ & $0.27 \pm 0.02$ \\
\hline BANDP & $0.51 \pm 0.08$ & $0.34 \pm 0.03$ & $0.40 \pm 0.02$ \\
\hline \multicolumn{4}{|l|}{ SL X } \\
\hline QUAL & $0.15 \pm 0.30$ & $0.01 \pm 0.03$ & $0.21 \pm 0.02$ \\
\hline ROC & $0.24 \pm 0.36$ & $-0.01 \pm 0.03$ & $0.01 \pm 0.02$ \\
\hline COL & $0.05 \pm 0.30$ & $0.04 \pm 0.03$ & $0.03 \pm 0.02$ \\
\hline YOLK & $-0.34 \pm 0.37$ & $-0.02 \pm 0.03$ & $-0.04 \pm 0.02$ \\
\hline STAPL & $-0.13 \pm 0.41$ & $0.05 \pm 0.03$ & $0.04 \pm 0.02$ \\
\hline BANDP & $0.40 \pm 0.32$ & $0.07 \pm 0.03$ & $0.09 \pm 0.02$ \\
\hline \multicolumn{4}{|l|}{ CV X } \\
\hline QUAL & $-0.50 \pm 0.06$ & $-0.12 \pm 0.04$ & $-0.27 \pm 0.02$ \\
\hline ROC & $-0.58 \pm 0.08$ & $-0.14 \pm 0.04$ & $-0.27 \pm 0.02$ \\
\hline COL & $-0.08 \pm 0.08$ & $-0.12 \pm 0.04$ & $-0.10 \pm 0.02$ \\
\hline YOLK & $-0.07 \pm 0.09$ & $0.10 \pm 0.04$ & $0.03 \pm 0.02$ \\
\hline STAPL & $0.45 \pm 0.10$ & $0.06 \pm 0.04$ & $0.16 \pm 0.02$ \\
\hline BANDP & $0.02 \pm 0.09$ & $-0.01 \pm 0.04$ & $-0.00 \pm 0.02$ \\
\hline \multicolumn{4}{|l|}{ FD X } \\
\hline QUAL & $-0.42 \pm 0.07$ & $-0.08 \pm 0.05$ & $-0.23 \pm 0.02$ \\
\hline ROC & $-0.38 \pm 0.09$ & $-0.13 \pm 0.04$ & $-0.21 \pm 0.02$ \\
\hline COL & $-0.10 \pm 0.07$ & $-0.06 \pm 0.05$ & $-0.07 \pm 0.02$ \\
\hline YOLK & $-0.08 \pm 0.09$ & $0.03 \pm 0.04$ & $-0.02 \pm 0.02$ \\
\hline STAPL & $0.60 \pm 0.08$ & $0.23 \pm 0.04$ & $0.31 \pm 0.02$ \\
\hline BANDP & $0.31 \pm 0.08$ & $0.20 \pm 0.04$ & $0.23 \pm 0.02$ \\
\hline
\end{tabular}

